\title{
Road, Bridge and Tunnel Engineering Construction Strengthening Technology of Grouting Method in Application
}

\author{
Pengtao Jin \\ Jilin railway vocational and technical college
}

\begin{abstract}
Keywords: Strengthening technique; Grouting method; Road, bridge and tunnel construction; Application
\end{abstract}

\begin{abstract}
Along with the advance of China's economic construction, highway Bridges, and other infrastructure is also more and more perfect, has the very big development potential. Highway, bridge and tunnel construction of major projects, such as the requirement of technology is very high, and has more stringent requirements for quality. In engineering construction, however, with more problems, such as the cracking of the tunnel, masonry is loose and mud loss, etc., and aiming at the problems in the construction, this paper also analyses also these common problems, put forward using the method of grouting to reinforce existing in highway, bridge and tunnel diseases, and introduces the reinforcement principle and concrete reinforcement technique measures.
\end{abstract}

\section{Introduction}

Along with our country economy has increased in recent years, the continuous improvement of science and technology, construction of cities and towns of all kinds of transportation engineering demand continues to increase. In highway bridge and tunnel construction by its, back to the use of some new technology, the accelerated steps of urban construction. However, there are also many problems in road, bridge and tunnel construction, which mainly includes the slurry falls off, loose masonry and tunnel cracks in three aspects. Highway, bridge and tunnel as a major construction project, the construction of extremely high quality requirements, is likely to be affected by any carelessness caused serious consequences, so it is very urgent to solve the construction problems. Grouting reinforcement method as a kind of mature technology, can effectively solve the above problems, the construction quality are guaranteed.

\section{Introduction of the Grouting Method and Principle of Construction}

Grouting method essence is the use of hydraulic, pneumatic or the principle of electrochemistry, can put some curing of grout injection of natural or man-made cracks, voids to improve technology and methods of various physical and mechanical properties of medium in the process of grouting, grout penetrated cracks and pores, will form the plasma column in the complete construction of composite, effectively improve the robustness of Bridges of and bearing force, to reduce the problem of uneven settlement of the bridge.

With What Is the Purpose of the Grouting Method. Grouting method, with the purpose of can be roughly divided into four, respectively is: a, plugging: plugging holes, prevent water; Second, seepage control: lower permeability, reduce the osmotic quantity, improve the ability of permeability, reduce pore pressure; Three, strengthening: improve the geotechnical mechanics strength and deformation modulus, restore concrete structure; Four, correct building skewness: make the uneven settlement of the building have taken place in restoring to the original a predetermined position, or reduce the buildings of skewness.

Using the Technology of Grouting Method. At present, the grouting technology is relatively mature and static pressure grouting method and high-pressure jet grouting method two kinds. Among them, the actual construction is most used in high pressure jet grouting method. High-pressure jet grouting method is mainly used to drill the enormous pressure slurry run to the fixed position of the soil layer, and then the pressure generated by professional equipment to jet grouting materials and grouting are ejected material has big pressure, speed, the characteristics of 
high energy, when the liquid flow in the soil structure, pressure can make the soil particles fall off, and grouting material components will fill the pore of inside body for higher strength consolidation, makes the roads and Bridges, tunnel engineering reinforcement effect. At present, the application range of grouting method gradually expand, such as underground construction, base, dam foundation, etc. Using the method of grouting can be good for these cracks and loose problem of the construction site, can be very good to improve engineering quality problem and safety performance.

\section{The Possible Problems in Highway, Bridge and Tunnel Construction}

Cracks. Cracks in concrete structures is one of the most common problems, road, bridge and tunnel engineering. The vast majority are due to the reason of crack on the concrete pouring process after the heat bilges cold shrink crack; Building of uneven settlement crack; Prestressed concrete bridge structure of internal cracks is due to more concrete aggregate do not conform to the requirements of the construction specification, silt content is too large or Jian JiLiao reaction produced by the crack; Insufficient strength of concrete grade, of non-vibrating concrete cracks caused by tight enough. The cracks of which there are may result in serious engineering quality and safety, even accidents may occur.

Masonry Is Loose. Because of loose abutment masonry to produce, will be the loss of lime, and lead to bridge according to stability of gravity.

Build by Laying Bricks or Stones Slurry Loss. Build by laying bricks or stones slurry has a very important role in the engineering construction. During the construction of highway, bridge and tunnel engineering, build by laying bricks or stones slurry can have the effect of reinforced wall, increases the stability of metope, can also have the beautification of the wall. If you build by laying bricks or stones fall off, can cause lost the original wall reinforcement effect, thus reducing its stability, also will reduce the safety factor.

Above, these problems are often encountered in the actual construction of the problem, if not timely and effective solution and prevention, it may cause damage to engineering, lead to major safety accident, grouting method, however, as a kind of mature and reliable reinforcement method, the above can be very good for solve these problems, improve the quality of engineering.

\section{Grouting Method of Reinforcement Design}

Road, bridge and tunnel engineering construction, to ensure that the quality of the reinforcement, ensure effective completion of this project, you should make a reasonable design and construction scheme. In the process of the actual construction of highway, bridge and tunnel, when choosing grouting construction period, construction personnel should be according to the severity of the highway, bridge and tunnel cracks is analyzed, and the analysis should also be considered when less than the construction period of the severity of the uneven settlement, in order to more clear and concise description of the grouting method in the importance of the application in highway, bridge and tunnel engineering, this paper specially selected the wadi foundation cracks occur around to analyses the effect after grouting.

Grouting construction of our country current regulation standard is divided into two aspects: one, the strength of grouting control standards, and second, the grouting construction quality control standards. Therefore, this requires during the construction of highway, bridge and tunnel, especially grouting was carried out on the bridge pier, the construction unit to guarantee the quality of grouting construction level, must according to the actual situation of the in the engineering construction to develop scientific and reasonable control standards. In our country, on the other hand, about the strength of grouting control standard content, if specified bridge pier cracks or gap and other issues, construction technical personnel after grouting construction pile bearing capacity, must conform to the requirement of strength control content stated value. In addition the forecast grout diffusion radius, the calculated according to the engineering actual situation, a single use formula to calculate and cannot effectively right reflect the actual problem. This is mainly because in the actual construction of highway, bridge and tunnel, there will be a lot of uncertain factors, may 
lead to pier in space, therefore, have a certain level of professional technical personnel when judge generally according to the actual situation, and on the basis of the actual situation, to evaluate the diffusion radius of make a concrete analysis. Such as when to evaluate radius of bridge pier, the construction technology personnel is on the basis of factors such as geological characteristics, typically determined in the range of $1 \mathrm{~m}$ to $1.5 \mathrm{~m}$.

\section{The Application of Grouting Method in Road, Bridge and Tunnel Engineering}

The Preparation for Construction. Before the engineering implementation of grouting method should do some preparation. First of all, the grouting scheme design. Grouting design must be included in the previous survey results and calculation, the selection of grouting method, grouting construction control standard, the ratio of grouting material and so on. And field survey, and make the relevant data records, and the calculation and analysis, to determine the parameters of the grouting operation; In accordance with the relevant control grouting construction by the state standards, and combined with the actual engineering construction, the grouting construction to make a scientific, reasonable and effective control standards; According to the actual circumstance of engineering and engineering cost to choose proper grouting material; Due to the liquidity of grouting materials, grouting radius and drilling area will influence the grouting scope, therefore, so must first consider the deciding factor to determine the scope of the grouting; According to the strength and properties of grouting materials, reasonable allocate pulp material ratio; Select the correct grouting method, according to the actual construction situation to choose corresponding grouting method for the construction, different grouting is applicable to different geological conditions, such as splitting grouting method can be used in the processing of hard soil layer, osmotic grouting method can be used for the processing of the gravel layer, intensity of pressure grouting method can be used to lower the low-level processing. Second, is to be prepared for construction machinery and pulp material. According to the needs of actual construction will be ready all construction machinery equipment and a variety of tools, at the same time, according to the construction plan design requirements to the construction need to use all kinds of grouting materials. Finally, there is the grouting construction before the grouting test preparation, before the grouting construction, should choose the corresponding test method, grouting experiment, clear distance and diffusion radius of grouting hole data, for the grouting construction provides uniform data standards.

The Construction Process of Grouting Method. After ready to personnel and equipment required for road, bridge and tunnel grouting of the entire working process is as follows: roughly drilling put slurry pipe and sealing orifice stir grouting grouting ready grouting for coagulation the seal.

Construction Technology of Grouting Method. Grouting method in construction of the highway, bridge and tunnel engineering construction technology should be in strict accordance with the order from top to bottom. When specific content is as follows: the grouting hole formation, should according to the actual construction need to choose the appropriate drill, construction, and take over a hole when the drill to cohesive soil, using the management guide hole wall, and then use bailing bucket sand into a hole, and drill into the cohesive soil. Should be used to avoid sediment into the tube, wrapped in soft rubber will cost the outer wall of pipe. In mixing, should to the mixing slurry into the corresponding amount of water in the tube, and evenly stirring, then test the standard amount of cement into the mixing tube for $3 \sim 5 \mathrm{~min}$. By pure pressure grouting method to make slurry grouting full fill and foundation, bridge and tunnel, in order to achieve the depth of the design requirements. At the end of the grouting, shall be immediately for hole sealing operation, hole sealing $24 \mathrm{~h}$

Grouting Method Related Matters Needing Attention. Grouting method in practical construction operation has high maneuverability, different projects for different locations, to choose different grouting materials and construction methods, but must ensure the quality of grouting, the grouting parameters control is the most important thing to notice. Need to calculate the control of 
the grouting parameters is as follows: the grouting pressure, grout diffusion radius and valid distance, serous solidification time. Combined with actual engineering conditions of determining grouting pressure needed to consider, if less pressure needed for the choice of chemical grouting or shallow grouting, if pressure needed for the choice of deep grouting or cement grouting. Because of slurry effective distance and diffusion radius can be directly affects project cost, need to consider in advance. Serous solidification time is related to the progress of the project, it has to do with choosing grouting material and the early stage of the engineering budget also have a contact, but can accurately estimate the solidification time grouting materials were determined, so as to accurately estimate the project progress.

\section{Conclusion}

To sum up, the grouting method has become a highway, bridge and tunnel engineering, the main construction method, it has the very high flexible mobility. Grouting method is not only the operation is simple and less affected by the weather factors. On highway road, bridge and tunnel grouting maintenance regularly, can also be very good solve the problem of engineering quality, reduce the engineering cost, prolong the service life of buildings. In the future in the road, bridge and tunnel construction, if you need to reinforce the construction, we should first consider using grouting method.

\section{References}

[1] Davis leung. Parse the application of grouting method in bridge and tunnel construction technology [J]. Journal of building materials and Decoration, 2012, (26) : 35

[2] Hai-yang wu. Highway, bridge and tunnel disease treatment method and device configuration study [J]. Journal of heilongjiang science and technology information, 2013 (4) : 246

[3] Nieguobin Fang Xinggang. Application of grouting method in road, bridge and tunnel construction [J] Through the world, 2013, (10) : 257-258.

[4] Sun Hu. The analysis of application of grouting method in road, bridge and tunnel construction [J]. Journal of heilongjiang province Transportation science and technology, 2013, (10) : 2013.

[5] Chen Zhuo. Application of grouting method in road, bridge and tunnel construction [J]. Transportation standardization, 2013, (8) : 139

[6] Wang junwork Zhao Jingchao, liu. Prestressed degree of mid-span variable coefficient and the influence of creep coefficient of immunity numerical relationship [J]. Journal of zhengzhou university: engineering science, 2013 (5) : 26 to 30

[7] Li Hanting. Analyses grouting method in the application of highway, bridge and tunnel construction [J]. Journal of technology development of the enterprise, 2014, (12) : 68 